University of Nebraska - Lincoln

DigitalCommons@University of Nebraska - Lincoln

Remote Access Mechanism Exploring Electronic Databases in Law Schools in India: A Lifeline during Covid-19 Lockdown

Akash Singh

akash@nludelhi.ac.in

Follow this and additional works at: https://digitalcommons.unl.edu/libphilprac

Part of the Legal Education Commons, and the Library and Information Science Commons

Singh, Akash, "Remote Access Mechanism Exploring Electronic Databases in Law Schools in India: A Lifeline during Covid-19 Lockdown" (2021). Library Philosophy and Practice (e-journal). 5746.

https://digitalcommons.unl.edu/libphilprac/5746 


\title{
Remote Access Mechanism Exploring Electronic Databases in Law Schools in India: A Lifeline during Covid-19 Lockdown
}

\author{
Dr. Akash Singh \\ National Law University Delhi, India \\ akash@nludelhi.ac.in
}

\begin{abstract}
Bar Council of India under Section 4 of Advocates Act 1961 passed by Indian Parliament, governs legal education and practice in India. Law Schools are approved and governed under the rules framed by Bar Council of India. Currently, India has twenty three law schools apart from more than 2000 law departments and colleges in India. Lockdown of academic institutions due to COVID 19 interrupted educational and research activities in law schools too. The paper here and now showcases a comparative study of usage of electronic contents by their patrons during pre-lockdown and lockdown period by remote access mechanism. The paper traces user various mechanisms used by law schools in India for remotely accessible of electronic databases. Usage patron of databases through remote access software and content based comparison of electronic databases have been evaluated in the paper for better understandings of tools and type of electronic contents used by law school patrons. The paper traces a comparison of mechanisms used by law schools in India for remotely accessible of electronic databases. The paper also sketches a number of findings based on user responses and contents in demand to suggest future planning and procurement of digital contents for strengthening base of legal education and research.
\end{abstract}

Keywords: Remote Access; Electronic Database; Law School; Law Library

\section{Introduction}

Law Schools play a vital role in imparting legal education and research in India. We may also address the stake of law schools supporting civilized social contribution while counting judicial officers, civil servants, top most litigation lawyers, law firm partners and obviously quality law teachers of current generation. Pandemic has also effected law school teachings, clinical trainings and physical sharing of experience, which too shifted in online mode. Majority of law schools in India, came up with proctored based or open book exams for students last year. The passing out students 
also missed various opportunities like trainings on the practical front and convocation emotional moment on the personal front.

The most important factors for imparting quality and effective legal education consist of a good interactive and reliable digital learning platform, a good repository of teaching and learning materials and obviously digital legal information resources supported by efficient remote access technology. A law school must not be lacking on the part of a good hybrid library having more and more stake of electronic documents with efficient information technology support mechanism.

\section{Review of Past Studies}

While explaining about lockdown of academic institutions, Cohen (2020) elucidates that this is a tough for law schools. He argues that, as even before the pandemic, the law schools were struggling with quality students, efficient pedagogy and scarcity of good teachers. He elaborates various platform using for online teaching and learning in law schools during lockdown period, which are supporting online diploma courses too. Kuris (2020) in another article "The Impact of Coronavirus on Legal Education" observes a greater impact of legal education in law school in United States. He point outs various difficulties like restrict access or suspension of classroom lectures, clinical activities, study abroad programs, exchange programs and restricted use of physical libraries.

On the other side, Huges (2020) finds overall growth of enrollment of law students in the year of pandemic. She involutes the remarks of Jefff Thomas, Executive Director of Legal Program, Kaplan Test Prep, who inform about a remarkable increase of law school aspirants in the pandemic year. Huges also point outs various initiatives initiated by various law schools for extending practical based experience to law graduates.

Mallaya (2020) observes a number of challenges posed by pandemic before legal education system in India. She quotes the letter of the Chairman of Bar Council of India to Chief Justice of India mentioning problems faced by law students while studying online. She further minutely states that online teaching, webinars, internships are more harmful for final year students, who need hands on practice for facing practical challenges ahead. On the other face,

Bhattacharjee (2020) indicates a number of positive sides of online legal education during lockdown. He suggests a number of lucrative efforts for development of legal education instead of electing foreign law degrees by post graduate law students. He stresses over introduction of more and more digital learning mechanism; adopting 
best digital learning tools; development of standardized curriculum to support digital learning methods; introduction of new specialized courses and obviously access of sound electronic resources supporting legal education. He point outs various adapted efforts not only in legal education and teaching but also in the Courts of Judicature to work online.

While talking about the online infrastructure, a report submitted by IDIA Charitable trust (2020), most of the students residing in rural or semi-rural areas face problems either related to electricity or internet or both. The report covers various issues raised related imparting and studying legal education on online mode viz. access of internet and infrastructural aspects; accessing study material; mode of evaluation; and problem faced by specially enabled students.

Greenhall (2020) in RLUK Report elaborates digital shifting action of libraries under COVID-19 challenging conditions. Greenhall talks about decisive actions for transition of libraries for remote workings with resource realignment. The report facilitates guidelines and suggestions towards enhancing skills and leadership ability of librarians and recommendations pertaining to procurement of digital contents for best and efficient services to users sitting remotely during pandemic period.

\section{Paradigm shift from Physical to Online}

Pandemic sounds bad and leave only ill memories when we look behind the time. This time, the world faced Nobel Corona Virus at a stage when, we have full of information and communication technology support. Like other educational institutions, law schools boosted best efforts serving their students during lockdown. Various online platform like Microsoft Teams, Zooms, Google Meet, Livestorm, Go to Meeting, Cisco Webex, Apache OpenMeetings and many more have been adopted and used for virtual learning classes. Obviously, these tools were already existed, but the best use of such platforms were visualized during this panic situation. If we evaluate the dissemination of legal information through digital support mechanism, most of the law schools are well versed providing access of commercial adopted databases with the help of remote access mechanism. A number of commercially enabled software and virtual private network (VPN) based technology have been used by law schools for extending access services to their clienteles.

\section{Problem Statement in Consideration}

The study gleans to the efforts made by law schools in India with a view to evaluate efficiency of facilitating information dissemination mechanism in digital environment 
by law schools libraries. The following problem statement has been drawn considering base of the research paper.

"Law Schools have no sound technical support system to serve their users accessing electronic databases subscribed and accessible within the wall of the library through remote access mechanism, which may serve users while outside campus and at the time of pandemic situation as well."

\section{Objectives of the Study}

The study focusses over a comparison of use of electronic databases through remote access mechanism by the users during pre-lockdown period and during the lockdown period due to COVID-19 breakdown. Primary cause to frame the study is to observe various types of mechanisms used by the law schools in India for imparting electronic content access to their clientele; to visualize users' behavior towards use of electronic databases through remote access mechanism; to access the contents mostly used by the users during lockdown period.

\section{Research Methodology}

The study derives over the data received from the remote access software used by the National Law University Delhi. A telephonic method of interaction has been used for collecting information about the use of remote access mechanism by twenty three law schools in India. Data collected has been represented in charts and figures based on percentile method. APA Style Manual $7^{\text {th }}$ edition, has been used for citing related studies referred in the paper.

\section{Mechanism for Remotely Accessible of Electronic Databases}

Academic intuitions witness variety of technology implantation flowing digital information imparting free flow of intellectual set of knowledge. Remote access software like EZProxy, Open Athens, Shibboleth, RemoteX, Remote Log, My Loft and Referead are few example of famously used tools for remotely access of IP based databases to academic communities affiliated with their respective law schools. Apart from such tools, Virtual Private Network or we can say proxy settings of institutional network for accessing outside of the Local Area Network or Wide Area Network, is another means of accessing IP based databases outside of the territory of the law school. Table 1 visualizes the patron of using remote access software by twenty three law schools in India extending services accessing databases subscribed and accessible within IP ranges. RemoteX Software is used by nine law schools for this purpose. Further, seven law schools depend on Virtual Private Network (VPN) 
developed for satisfying access needs. Remote Log is used by three law schools and EZ Proxy is availed of by two law schools. Newly introduced software like My Loft and Refread is also maneuvered by one-one law schools in India.

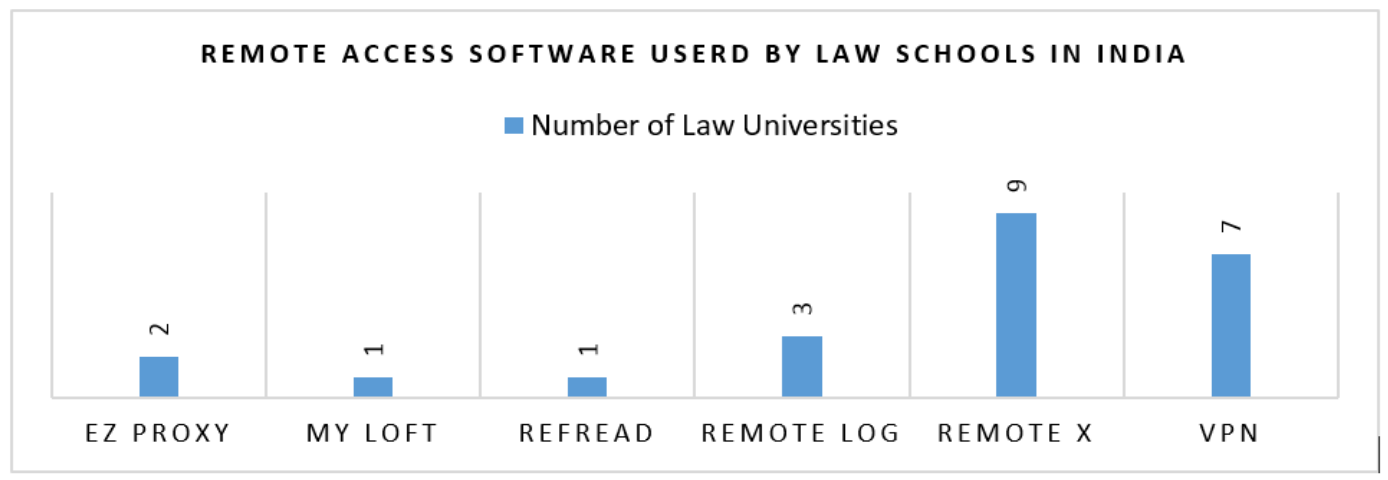

Figure 1: Remote Access Software used by Law Schools in India

\section{Access Mechanism Used in National Law University Delhi}

National Law University Delhi (NLUD) is a premier law school established in 2008 by the Act no.1, 2008, Government of NCT Delhi. In a very short of span, this law school achieved a number of feathers of success and is counted at number two in India. Few ranking agencies counts NLUD at number one or three too. This is very proud of to share that NLUD students achieved positions in not only at national level, but they also won international moot court competition based on resources. Since first passing batch of 2013, students hold key positions in administration, judicial system, and multinational companies and come up startups with international reputes.

NLUD beholds a state of the art library accommodates highly standard hybrid collection of legal information. Though few law schools have adopted remote access technology recently, NLUD extends remote access facility to its students since 2014 through RemoteX software. The software is based on cloud server and provides its service $24 X 7$ with minimal disturbance or lockdown.

\section{Usage Patron of Databases through Remote Access Software}

The phrase "Necessity is the Mother of Invention" stands suited for those who are availing remote access facility for education and research purpose within the wall of their residence during lockdown due to COVID 19 pandemic. We must take in mind that the majority of Law Schools in India are residential and students have to stay in hostels. Students use remote access facilities during vacation or when they are outside campus for any competition events like moots, debating, and essay writings. 
The paper presents a comparative study of two years of usage data collected based on databases used by the patrons of the NLUD through RemoteX software.

Table 1 envisions a comparative data of usage of electronic databases during lockdown covering period from March 17, 2020 to March 16, 2021), the period, educational institutions observed permanent closing of its academic activities in physical mode. Statistics for the period of one year before lockdown i.e. 17 March 2019 to 16 March 2020, have been accounted for envisaging a comparison of usage of such databases during lockdown period based of parameters like users, logins, downloads in numbers and megabyte and data browsed.

Table exhibits that before the period of lockdown, 13790 user availed remote access of databases for their academic purposes. The number got almost double by 31578 during the lockdown period, which is noted as more than 128 per cent increased in usage. If we looks on the logins, the users made 26275 logins in pre-lockdown period in consideration in comparison of 54175 during the lockdown period. Again if, we evaluate soaring in logins, 106.1846 per cent escalation has been recorded.

Around 14392 documents were downloaded before lockdown period as compare to 39556 during lockdown. If we count documents download comparison, an increase of 25164 document (174.8471 per cent) has been noted during lockdown period. Nevertheless, increase in downloads of papers in number has impacted on total downloading of data in megabyte. Around 30786 megabyte data has been downloaded during lockdown which shows an increase of 157.6139 per cent as comparative to pre-lockdown period. The condition is same, while observing data browsed during the two periods. Net increase in browsing of data is counted as 194138.37 megabyte which is almost 160.5421 per cent more as comparison to prelockdown period.

\begin{tabular}{|c|l|r|r|r|r|}
\hline S.n. & \multicolumn{1}{|c|}{ Parameters } & $\begin{array}{c}\text { Pre-Lockdown } \\
\text { (March 2019-March-2020) }\end{array}$ & $\begin{array}{c}\text { Lockdown } \\
\text { (March 20 to March 21) }\end{array}$ & $\begin{array}{c}\text { Usage } \\
\text { Increased } \\
\text { (In Numbers) }\end{array}$ & $\begin{array}{c}\text { Usage } \\
\text { Increased } \\
\text { (In per cent) }\end{array}$ \\
\hline 1. & Users & 13790 & 31578 & 17788 & 128.992 \\
\hline 2. & Logins & 26275 & 54175 & 27900 & 106.1846 \\
\hline 3. & $\begin{array}{l}\text { Total Downloads } \\
\text { (In Numbers) }\end{array}$ & 14392 & 39556 & 25164 & 174.8471 \\
\hline 4. & $\begin{array}{l}\text { Download Data } \\
\text { (in MB) }\end{array}$ & 19532.87 & 50319.39 & 30786.52 & 157.6139 \\
\hline 5. & $\begin{array}{l}\text { Browsing Data } \\
\text { (in MB) }\end{array}$ & 74513.23 & 194138.37 & 119625.14 & 160.5421 \\
\hline
\end{tabular}

Table 1: Comparative Analysis of Usage of Databases 
A graphical presentation of comparison of the usage of databases during prelockdown period and post lockdown period has been demonstrated in figure 2 . The chart clearly visualizes the surging of usage of electronic databases during the lockdown period. Bar one which represents data pertaining to pre-lockdown period and bar two constitutes data related to Lockdown period. The size of bars are selfexplanatory portraying a big difference of usage of electronic databases in two time slots.

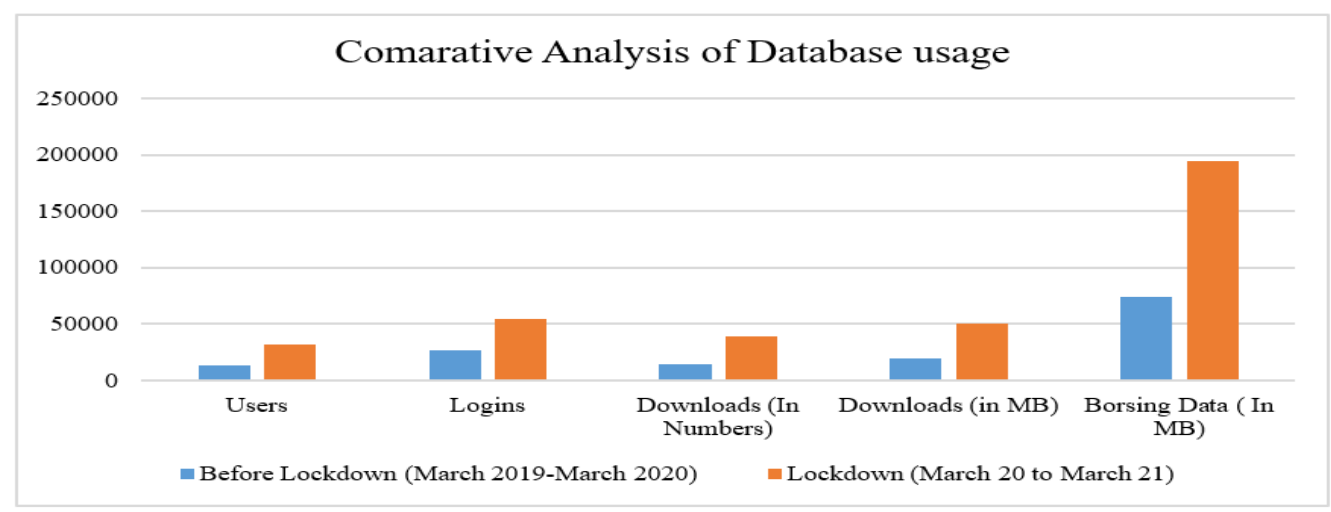

Figure 2: Comparative Analysis of Database Usage

The Figure visualizes a big enhancement of browsing of data during lockdown period with more downloading, increase number of downloads and more and more logins by users.

\section{Remote Users during Lockdown Period}

Lets evaluate the data under figure 3, which shows usage of Databases through remote access mechanism by various category of users during lockdown like undergraduates, postgraduates, research scholars, exchange students, research associates, and teachers. The figure visualizes that undergraduate users have availed benefits of remote access mechanism for accessing electronic information mostly as compare to other category of users. Among all users, 66 per cent of the users used remote access mechanism for using electronic databases pertain to the category of undergraduates. 


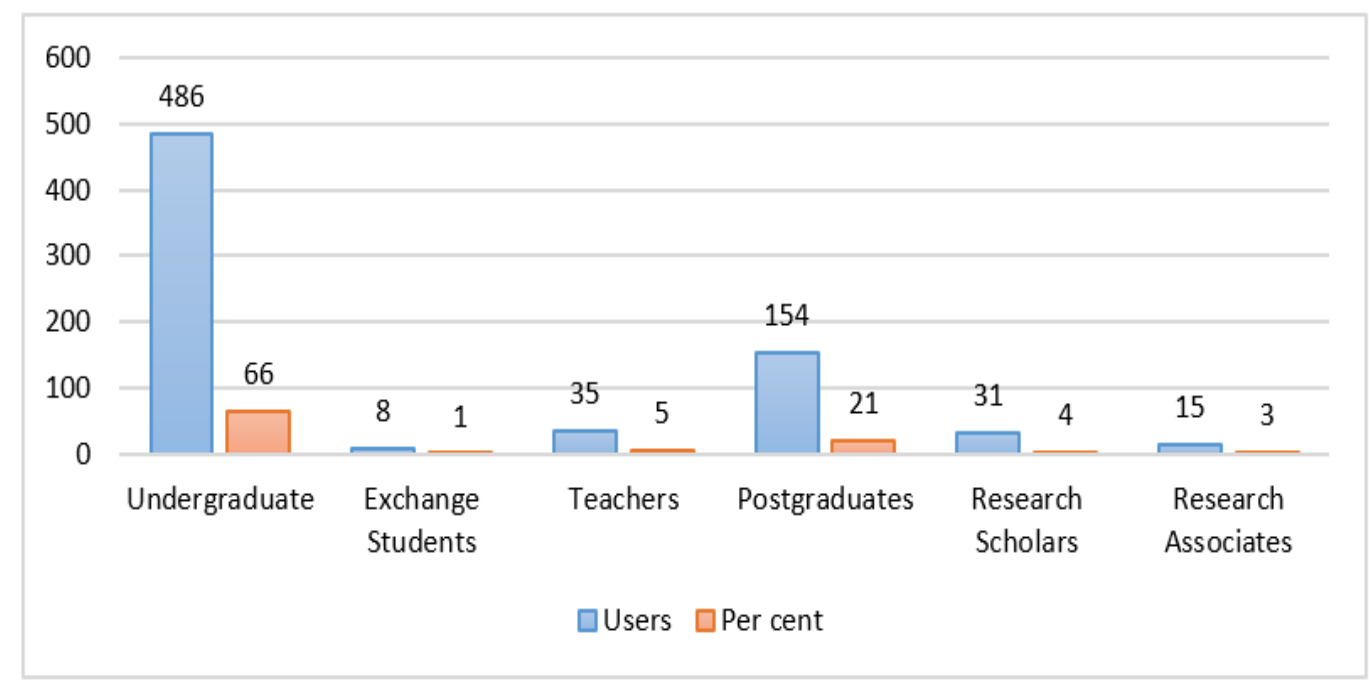

Figure 3: Number of Users under user Categories used Access Mechanism during Lockdown

Figure also shows that exchange students and research associates have less usage as compare to other categories.

\section{Remote Logins during Lockdown Period}

In figure 3, we observed that undergraduate students have edge using electronic databases during lockdown period. Figure 4 envisions logins by various categories of the users. The undergraduate students have made logins for 76.85 per cent and rest five categories have attempted to under rest 23.15 per cent of total logins.

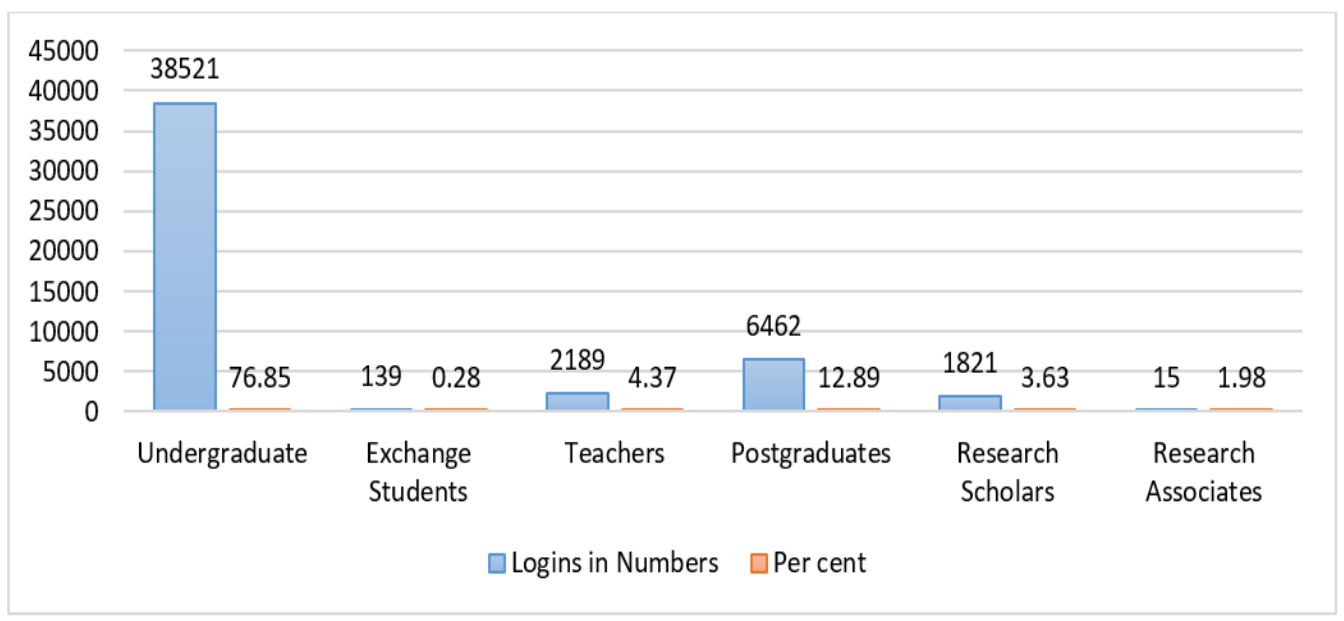

Figure 4: Logins during Lockdown Period 
Postgraduate students have accessed databases through remote access mechanism by 12.89 percent and have been recorded as second category, who used remote access mechanism during lockdown for accessing electronic legal information.

\section{Downloads during Lockdown Period}

Figure 5 proclaims that total 38187 documents were downloaded during the lockdown. Exchange students (128 downloads) and research associates (551) have been observed downloading the least downloading of documents. Out of the total downloads of the documents, undergraduate students have downloaded (65.02 per cent) most of the share of the documents.

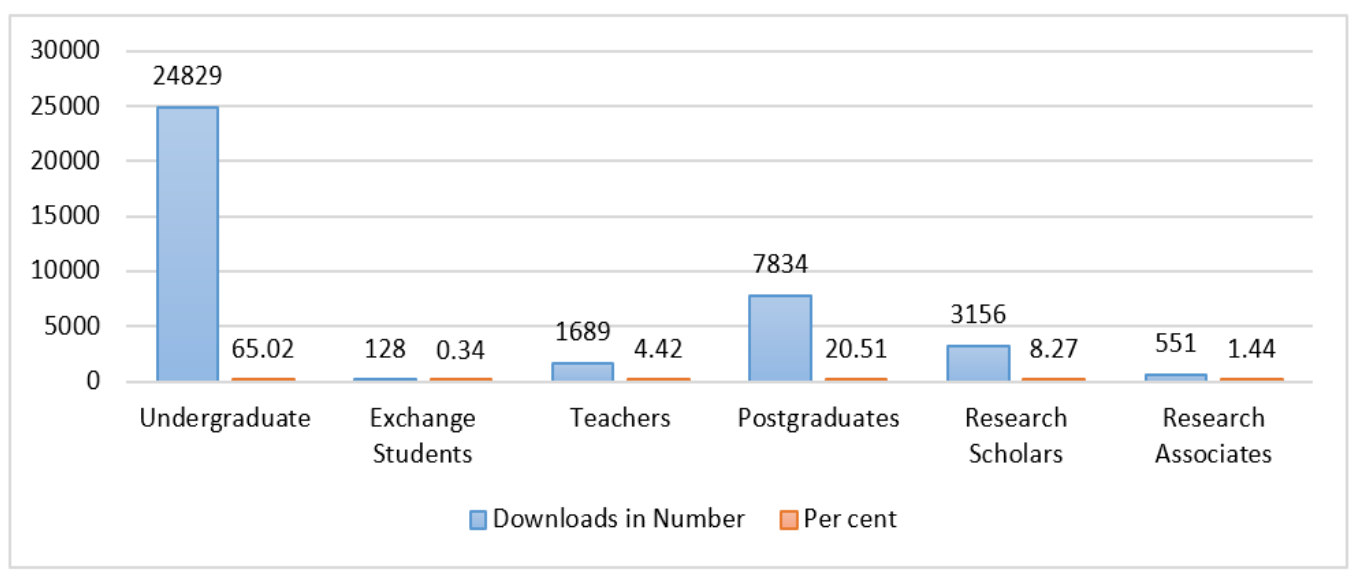

Figure 5: Logins during Lockdown Period

Again, it has been observed that undergraduate students have downloaded around one fifth share of the total number of downloads during the lockdown period.

\section{Content based Logins in Databases}

NLLUD Library provides access of variety of electronic contents including electronic books, comprehensive or hybrid databases, subject based databases, electronic journals and the databases provided access of case laws. Hybrid databases are those databases, which contain data sets pertaining to more content categories e.g. LexisNexis and Westlaw databases provide access to case laws, electronic journals, electronic books, commentaries and other analytical contents on multiple subjects and sub-disciplines. Subject based databases are those databases, which accommodate contents on a particular subject e.g. taxmann.com provides access of contents based on Taxation. Case law databases are he databases used to search case laws. Electronic books and electronic journals too has its direct access points controlled by publishers in a unique separate manner. 


\begin{tabular}{|l|r|r|r|}
\hline \multicolumn{1}{|c|}{ Name of Database } & $\begin{array}{c}\text { Unique Logins } \\
\text { 2019-2020 }\end{array}$ & $\begin{array}{c}\text { Unique Logins } \\
2020-2021\end{array}$ & \multicolumn{2}{c|}{$\begin{array}{c}\text { Per cent } \\
\text { Increase }\end{array}$} \\
\hline Electronic Books & 1309 & 2972 & 127 \\
\hline Database (Hybrid) & 11825 & 26299 & 122 \\
\hline Database (Subject) & 4200 & 6424 & 175 \\
\hline E-Journals & 791 & 2176 & 136 \\
\hline Database (Case Law) & 18438 & 43525 & \\
\hline
\end{tabular}

Table 2: Comparative Analysis of Usage of Databases

Table 2 manifests comparison of contents access by patrons by logins during prelockdown and during the lockdown period. Table reveals that the logins of electronic journals have been increased by 175 per cent as compared to pre-lockdown period, which is highest among all categories of contents. Although electronic books, hybrid databases and case law based databases logins have been noticed to increase by 127 per cent, 122 per cent and 136 per cent respectively. Subject based databases, however in count in numbers have been accessed by 2224 logins more as compare to pre-lockdown period.

\section{Content based Downloads in Databases}

Enhancement of downloads of documents have been observed in databases during the comparative period. Electronic books have been perceived an increase of 166 per cent, which is higher downloads among all categories of the databases. The downloads from hybrid databases are remarkable too where 166 per cent more documents have been download in the lockdown period by the patrons.

\begin{tabular}{|l|c|c|c|}
\hline \multicolumn{1}{|c|}{ Name of Database } & $\begin{array}{c}\text { Downloads in } \\
2019-2020\end{array}$ & $\begin{array}{c}\text { Downloads in } \\
2020-2021\end{array}$ & $\begin{array}{c}\text { Per cent } \\
\text { Increase }\end{array}$ \\
\hline Electronic Books & 1002 & 2666 & 166 \\
\hline Database (Hybrid) & 11208 & 29483 & 163 \\
\hline Database (Subject) & 1288 & 2858 & 122 \\
\hline E-Journals & 516 & 812 & 57 \\
\hline Database (Case Law) & 3773 & 6972 & 85 \\
\hline
\end{tabular}

Table 3: Comparative Analysis of Usage of Databases

Electronic journals, case law based databases, however, have been espied increase of 57 per cent, 85 per cent and 122 per cent respectively. If we observe on the quantum of downloads in terms of numbers, hybrid databases have edge downloading most of the document (29483) during lock down period. 


\section{Observation and Findings}

Bellamy and others (1991) discussed about remote access to electronic services including electronic information request form, electronic bulletin services and access of electronic databases accessible through out campus network. They mentioned about the networking support of access of such databases within campus. Such ideas of accessible databases beyond boundary walls of libraries, could be considered as the mother of idea of accessing electronic databases from anywhere of the world. Discovery of World Wide Web and TCP \IP protocols, resulted in free flow of information through internet technology. Access of electronic databases based on Internet protocols, increased worldwide access possibilities of digital information. Proxy servers and cloud server technologies played vital role in development of remote access mechanism. The findings on the basis of data accumulated are bestowed as under.

\section{Mechanism for Remotely Accessible of Electronic Databases}

Law schools in India use remote access mechanism design and developed by commercial vendors and virtual private network mechanism as well. Majority of the Indian law schools use RemoteX software, which is a cloud based access mechanism. However, virtual private network is also used by seven law schools for supporting remote access mechanism. Inference of the data compression shows that most of the law schools use cloud based remote access mechanism for 24X7X365 support system.

\section{Usage Patron of Databases through Remote Access Software}

On the basis of data collection of usage of National Law University Delhi in two periods i.e. pre-lockdown period and during lockdown period, data shows that there is tremendous increase in use of electronic databases. More than 128 per cent users were noticed initiating of use of remote access mechanism during lockdown. There is immense escalation in number of logins, downloading and browsing of data during lockdown period. It is deducted that, the remote access mechanism has played a major role in support of education and research activities.

In obedience to data collected and evaluated, it is visualized that among various categories of users (undergraduates; exchange students; teachers; postgraduates; research scholars; and research associates), undergraduates (66 per cent) students have edge in using electronic databases through remote access mechanism during lockdown period. On the other side, undergraduate students have also made logins (76.85 per cent) and downloaded data (65.02 per cent) mostly as compare to other categories. 


\section{Content based Comparison of Electronic Databases}

Based on comparison of logins by users for accessing type of contents during pre and post lockdown, this is extrapolated that the usage of Electronic journals has been made logins (175 per cent) most as compare to other contents. If we evaluate other contents like electronic books (127 per cent), hybrid databases (122 per cent), subject based databases ( 53 per cent), increase in usage have also been noticed. We can withdraw conclusion that electronic journals whether downloading, browsing or online reading, have its edge to use during lockdown period. On the basis of this finding, we can suggest to subscribe or make it available more electronic journal contents for law school users. On the other side, while evaluating the data based on number of downloads, data from hybrid databases has been downloaded more as compare to other contents. If, we count increase in use of content in per cent, access of electronic books has been increased by 166 per cent during lockdown period.

\section{Suggestions and Recommendations}

Jayalakshmi and other (2018) discuss about perception and satisfaction level of remote access users. They come up with suggestions like need for improvement of the remote access services, seamless demand of electronic resources by users and need for day to day support for facing technical assistance. In conformity with findings of the study, a number of suggestions may be coined for best and effective use of electronic databases access services based on remote accesses mechanism.

The study suggests that law schools must look more focus of implementing most advanced remote access mechanism coping with serving best information dissemination techniques. The best remote access mechanism is the only measure strengthening sound legal information dissemination system supporting quality legal education and research in critical lockdown conditions and in case of need accessing resources from outside in general conditions as well.

The findings based on the usage of electronic databases by different categories of users, only the undergraduate students have been noticed to explore electronic database mostly. However, it is suggested and recommended to organize and fame more and more library user orientation sessions and mechanism for all categories of users for educating use of remote access mechanism exploiting electronic databases on optimum level by all category of users.

The study also suggests to enhance variety of electronic content based collections. Statistics shows that electronic journals and Hybrid databases which also provide access of electronic journals, were used more during lockdown period through 
remote access mechanism. This is suggested and recommended for procure more databases providing electronic journals supporting advanced research activities in law schools.

\section{Conclusion}

Kaup and others (2020) elaborates various majors over sustainability over academics during COVID 19 pandemics. They have discussed virtual classrooms, e-seminar based discussions, and webinars based professional interaction platforms, open online courses and electronic open and commercially enabled information resources. The paper traces implacability of information and communication technology based mechanism adopted by various law schools in India for extending accessibility of electronic legal databases with no boundary. The students and faculty of the law schools have explored more electronic contents, especially electronic journals and hybrid databases during lockdown period. It can be traced that the lockdown period has also been perfectly utilized by law school patrons for research and education activities with the help of remote access mechanism adopted for accessing internet protocol based electronic databases. It is greatly tracked down that the subscription of electronic journals, electronic books and hybrid databases, which have been used more during lockdown period, must be procured by the law schools to increase accessibility strength of law school libraries. The paper delineates new future possibilities of multi-disciplinary research of library and computer science assessing probability of enhanced remote access mechanism to support access to electronic databases efficiently. Law schools, known for its quality imparting legal education and research to sustain with international law and regulations, would certainly perform at part with foreign law schools, having better accessibility of legal databases with standard contents around the globe to their patrons.

\section{References:}

Bellamy, L.M., Silver, J.L. and Givens, M.K. (1991). Remote Access to Electronic Library Services through a Campus Network. Bulletins of the Medical Library Association. 79.1: 53-62. 
Bhattacharjee, Ripon (2020, 3 August). COVID 19 Overhauls Legal Education breaching its Long Forfeited Walls. Accessible at http://adamasuniversity.ac.in/covid-19-overhauls-legal-education-breaching-itslong-fortified-walls/

Cohen, Mark A. (2020, 13 August) Post Pandemic Legal Education. Forbes. Accessible at https://www.forbes.com/sites/markcohen1/2020/08/13/post-pandemic-legaleducation/?sh=74f6408f75d2

Greenhall, M. (2020). Covid-19 and the digital shift in action, RLUK Report. Accessible at https://www.rluk.ac.uk/wp-content/uploads/2020/06/Covid19-and-the-digitalshift-in-action-report-FINAL.pdf

Hughes, Joanna (2020, 27 August). How have Law Schools Increased Enrollment amid Covid? KEYSTONE Law Study. Accessible at https://www.lawstudies.com/article/how-have-law-schools-increased-enrollmentamid-covid/

IDIA (2020, 24 September). Making Online Education Accessible and Inclusive in the Time of COVID 19 Pandemic. IDIA. Accessible at https://www.idialaw.org/blog/making-online-education-accessible-and-inclusivein-the-time-of-covid-19-pandemic/

Jayalakshmi, Rao, Mahabaleshwara and K, Shivananda Bhat (2018). Perception and Satisfaction Level of Remote Login Access Users: A Study. Library Philosophy and Practice (e-journal). $1783 . \quad$ Accessible at https://digitalcommons.unl.edu/libphilprac/1783

Kaup, Soujanya, and others (2020). Sustaining academics during COVID-19 pandemic: The role of online teaching-learning. Indian Journal of Ophthalmology. 68.6: $1220-1221$.

Kuris, Galbriel (2020, 24 August). The Impact of the Coronavirus on Legal Education. US News and World Report. Accessible at https://www.usnews.com/education/blogs/law-admissionslowdown/articles/the-impact-of-the-coronavirus-on-legal-education

Mallaya, Susmitha P. (2020). Countering Legal Education in India: An Analysis of Challenges Posted by Covid-19. ILI Law Review. Special Issue: 147-161p. 